\title{
Selection of optimal cutting conditions for pocket milling using genetic algorithm
}

\author{
Saurabh Aggarwal • Paul Xirouchakis
}

Received: 20 April 2012 / Accepted: 16 August 2012 / Published online: 1 September 2012

(C) Springer-Verlag London Limited 2012

\begin{abstract}
Pocket milling is the most known machining operation in the domains of aerospace, die, and mold manufacturing. In the present work, GA-OptMill, a genetic algorithm (GA)-based optimization system for the minimization of pocket milling time, is developed. A wide range of cutting conditions, spindle speed, feed rate, and axial and radial depth of cut, are processed and optimized while respecting the important constraints during high-speed milling. Operational constraints of the machine tool system, such as spindle speed and feed limits, available spindle power and torque, acceptable limits of bending stress and deflection of the cutting tool, and clamping load limits of the workpiece system, are respected. Chatter vibration limits due to the dynamic interaction between cutting tool and workpiece are also embedded in the developed GA-OptMill system. Enhanced capabilities of the system in terms of encoded GA design variables and operators, targeted cutting conditions, and constraints are demonstrated for different pocket sizes. The automatically identified optimal cutting conditions are also verified experimentally. The developed optimization system is very appealing for industrial implementation to automate the selection of optimal cutting conditions to achieve high productivity.
\end{abstract}

\section{S. Aggarwal $(\square)$}

EPFL STI IGM LICP, ME B1 344,

Station 9, Lausanne, Switzerland

e-mail: saurabh.aggarwal@epfl.ch

\section{P. Xirouchakis}

EPFL STI IGM LICP, ME A1 408,

Station 9, Lausanne, Switzerland

e-mail:paul.xirouchakis@epfl.ch
Keywords Optimization • Genetic algorithm • Cutting conditions • Pocket milling • Chatter vibration • Machining time

\section{Introduction}

Pocket milling plays an integral part in the machining domain, e.g., in die, mold, aerospace, automotive parts, etc. Almost $80 \%$ of the milling operations to produce final parts are produced by numerically controlled (NC) pocket milling [1]. A pocket is generated by sweeping a cylindrical cutting tool along a predefined toolpath. Most CAD/CAM systems have existing toolpath routines like linear, spiral, and zigzag. Linear toolpaths, with the advantage of maintaining constant radial depth of cut, same feed direction, and consistent milling mode along the toolpath, are also one of the most used toolpaths in the pocket milling [2]. At process planning stage, toolpath routine requires cutting conditions, axial and radial depths of cut for geometrical definition of toolpaths, and corresponding spindle speed and feed rate for cutting tool movement along the toolpath, to generate the NC codes for actual cutting. The right selection of cutting conditions for an assigned machine tool/spindle/tool holder/cutting tool/workpiece material system plays a vital role during process planning. In the production floors, the selection of cutting conditions is partly left to the process planner's experience and guidelines available in the catalogues of machine tools and cutting tools which does not ensure optimal selection of the cutting conditions [3]. Currently, part programs are generated with a long overall preparation time and with rather "slow" machining time performance in terms of fully exploiting 
the capabilities of the modern machine tool system. Moreover, wrong selection of cutting conditions often leads to chatter vibrations, high cutting forces, poor surface finish, cutting tool wear, and even reduction in the spindle working life. The main objective of the process planner is to identify the cutting conditions which yield lower machining time without any trial and error.

A number of studies have been executed for the selection of optimal cutting conditions using artificial intelligence techniques. Rai et al. [4] used a genetic algorithm approach to optimize material removal rate for multitool milling operations. Sönmez et al. [5] have presented geometric programming approach for the selection of cutting conditions for the maximization of production rate. Dereli et al. [6] optimized cutting conditions for milling operations taking unit cost as an objective function. Tandon et al. [7] developed a method, based on evolutionary computation, to optimize machining time by optimizing only spindle speed and feed rate. Shunmugam et al. [3] presented a method for optimal cutting conditions in multipass face milling while considering constraints such as dimensional accuracy, surface finish, tool wear, and machine tool capabilities. Baykasoğlu and Dereli [8] have presented an excellent approach for the optimal number of cutting passes for multipass machining. Wang et al. $[9,10]$ have presented a method based on genetic simulated annealing to optimize production time for multipass milling. All the above-mentioned studies did not consider the most important technological constraint, stability during milling process, and also lack in targeted cutting conditions and practical constraints in their optimization systems.

Chatter, which develops due to the dynamic interactions between cutting tool and workpiece, is the most undesirable and complex phenomenon during milling process. Chatter lowers the surface quality of the workpiece, reduces spindle's and cutting tool's working life, and thus affects significantly the overall productivity of the machining process [11]. Several studies have been performed since late 1950s concerning the stability of machining process. The theory of chatter in metal cutting was first established by $[12,13]$. Merritt [14] has presented a foundational understanding of self-excited vibrations. Chatter (often referred as selfexcited vibrations) caused by the regenerative effect is the most important cause of instability during milling operations [15]. Many researchers have presented the detailed reviews of various studies related to the modeling and prediction of chatter vibrations [16-19]. It is concluded that Altintas and Budak [20] present an indispensable study for the predication of stable limits during milling. The selection of cutting conditions from the predicted stable limits at the process planning stage ensures chatter-free milling.

Tekeli and Budak [21] have presented a method to minimize the number of cutting passes for pocket milling by selecting chatter-free axial and radial depths of cut. For a given machine tool/spindle/tool holder/ cutting tool system and pocket, pocket milling time depends also on the selection of spindle speed and feed rate along with the number of passes (axial and radial depths of cut). Real optimization can only be achieved by considering all cutting conditions, spindle speed, feed rate, axial and radial depths of cut, and practical constraints of machine tool/cutting tool/workpiece system simultaneously [22].

The cutting conditions have a complex nonlinear relationship in affecting the physical limits of the machine tool, cutting tool, and workpiece system $[16,19]$. A computationally efficient genetic search algorithm is used as an optimization method. In the present work, GA-OptMill, a genetic algorithm (GA)-based optimization system for minimization of pocket milling time, is developed to automate the selection of optimal values of cutting conditions. The permissible bending stress and deflections of the cutting tool and operational limits of spindle speed and feed, available cutting power and torque of machine tool system, stability limits for chatter-free milling, and clamping load limits for workpiece system are implanted as constraints in the developed optimization system.

The developed optimization system is detailed in Section 2. The details of the embedded constraints are presented in Section 3. Details of the definition of search space, encoding of cutting conditions, and various GA operators used in the developed system are presented in Section 4. Simulation results and experimental validation of the optimal cutting conditions selected by the developed optimization system are presented in Section 5.

\section{System architecture}

The overall architecture of the developed GAOptMill system is presented in Fig. 1. The cutting tool specifications; cutting force coefficients for the specified cutting tool and workpiece material combination; operational limits of spindle speed, feed rate, available spindle power, and torque of the machine tool; and dimensions of the pocket can be entered directly by the process planner or taken from the database. Experimentally measured frequency response functions at the cutting tool tip in feed and normal to feed directions are loaded in the GA-OptMill system. 
Fig. 1 System architecture of the developed optimization system (GA-OptMill)

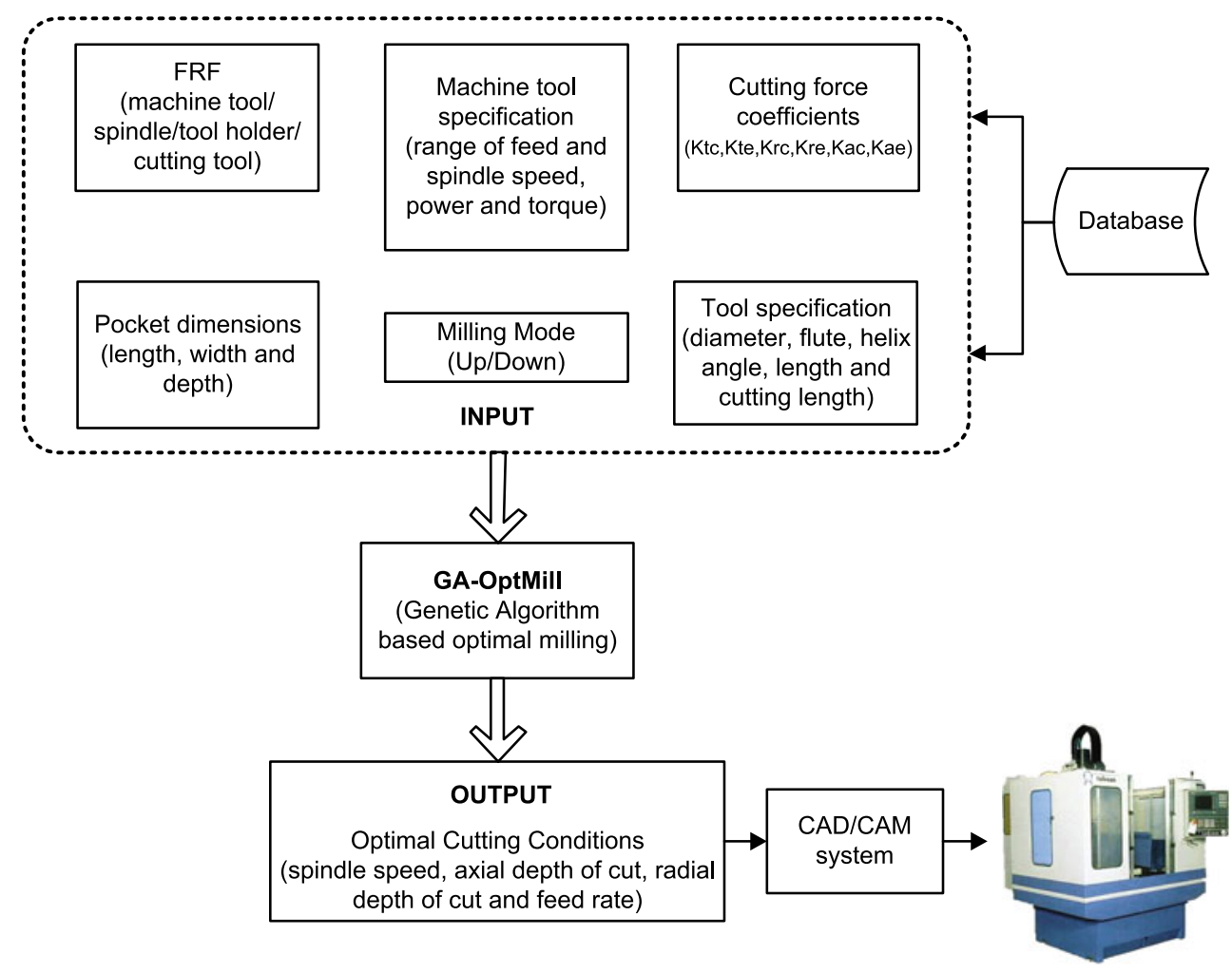

The favorable mode (up/down) during pocket milling is selected by the process planner. Pocket dimensions and toolpath strategy are presented in Fig. 2. The first slot pass is inevitable. Radial and axial depths of cut are required for the geometrical definition of the toolpaths. Total number of linear passes (nop) required for complete pocket, which depends on the number of radial passes (norp) for selected radial depth of cut and axial passes (noap) for selected axial depth of cut, are given by

$$
\text { nop }=\underbrace{\operatorname{ceil}\left(\frac{W_{\mathrm{p}}-2 D}{A_{\mathrm{e}}}\right)}_{\text {norp }} \underbrace{\operatorname{ceil}\left(\frac{D_{\mathrm{p}}}{A_{\mathrm{p}}}\right)}_{\text {noap }} \text {. }
$$

Spindle speed and feed rate are used to define the movement of cutting tool along the toolpath. Acceleration and deceleration of the machine tool feed axis affects the commanded feed rate (in millimeters per minute). The effect of acceleration/deceleration on the machining time is taken into account by considering the trapezoidal velocity profile of feed rate along the linear passes.

For a given set of inputs of machine tool/spindle/tool holder/cutting tool system and pocket, machining time depends on the selection of cutting conditions and is given by Eq. 2:

$T_{\mathrm{mac}}=\operatorname{nop}\left[\frac{f}{A}+\frac{L_{\mathrm{p}}-2 D}{f}\right] 60$.
Here,

$$
f=n N f_{\mathrm{t}}
$$

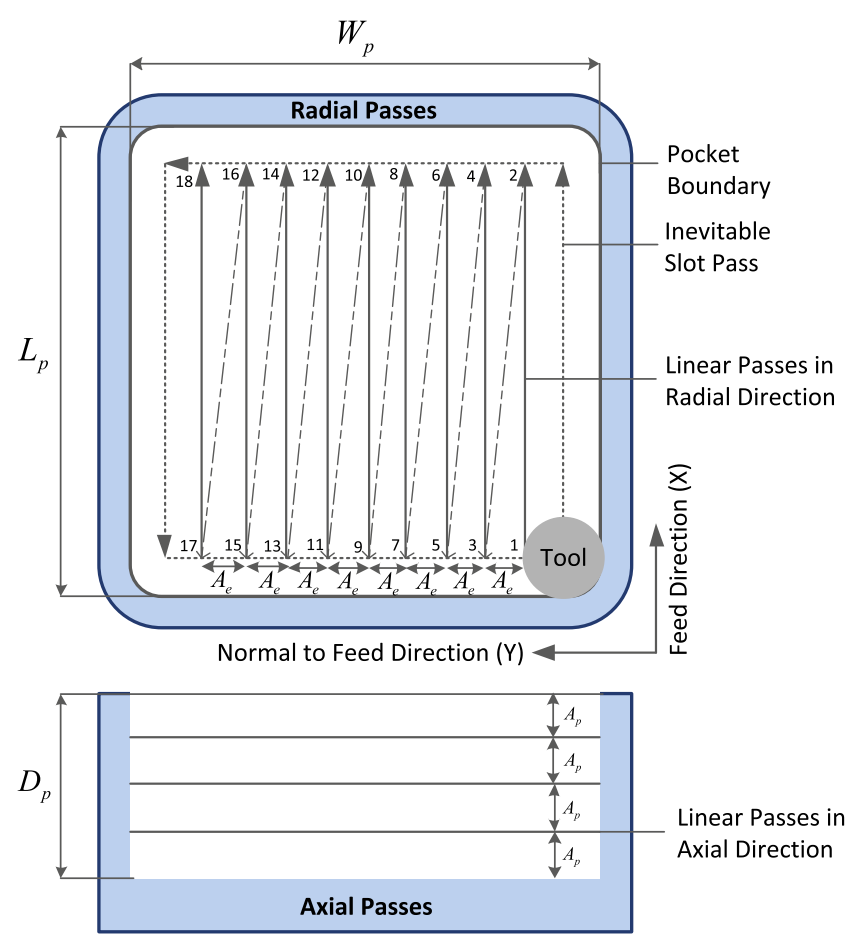

Fig. 2 Pocket dimensions and toolpath strategy 
where $T_{\text {mac }}$ is the machining time in second, $A_{\mathrm{p}}$ is axial depth of cut in millimeter, $A_{\mathrm{e}}$ is the radial depth cut in millimeter, $f$ is the feed rate in millimeters per minute, $f_{\mathrm{t}}$ is the feed rate in millimeters per (revolution-flute), and $n$ is the spindle speed in revolutions per minute. $D$ denotes the diameter of the helical end mill in millimeter and $N$ is the number of flutes of the cutting tool. $L_{\mathrm{p}}, W_{\mathrm{p}}$, and $D_{\mathrm{p}}$ are the length, width, and depth of the pocket in millimeter, respectively. ceil is the round-up function. $A$ is the acceleration/deceleration value of the machine tool feed axis in millimeters per $\left(\right.$ minute $\left.^{2}\right)$.

\section{Embedded constraints}

In the present work, the pocket milling time is minimized by respecting the various operational, technological, and dynamic constraints which are detailed in the following subsections.

\subsection{Cutting force, power, and torque}

Cutting forces during milling depend on the cutting tool geometry, workpiece material, and the cutting conditions. For a given set of inputs to the optimization system, the cutting tool and workpiece material remain the same. Therefore, the mechanistic model is used for the prediction of the cutting forces at different cutting conditions $[23,24]$. The geometry of the helical end mill is shown in Fig. 3. $D$ denotes the diameter of the end mill and $\beta$ represents the helix angle. The geometry of chip formation is shown in Fig. 4. The instantaneous chip thickness is given by Eq. 4 :

$h\left(\phi_{j}\right)=f_{\mathrm{t}} \sin \left(\phi_{j}\right)$

where $f_{\mathrm{t}}$ denotes the feed rate in millimeters per (revolution-flute) and $\phi_{j}$ denotes the instantaneous

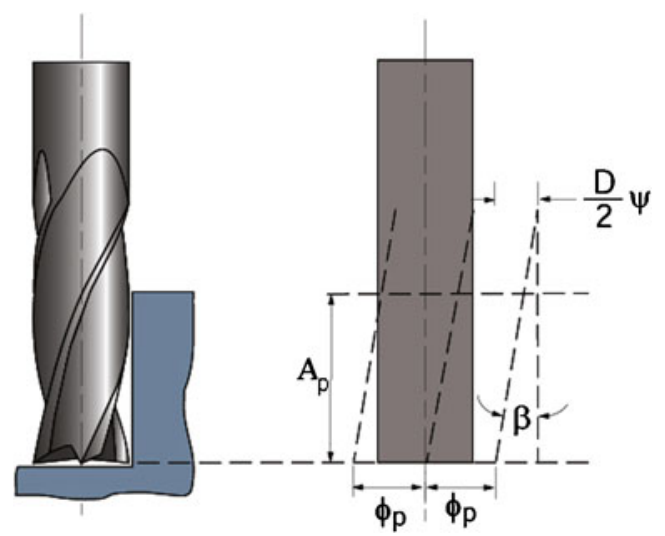

Fig. 3 Geometry of a helical end mill, redrawn from [24]
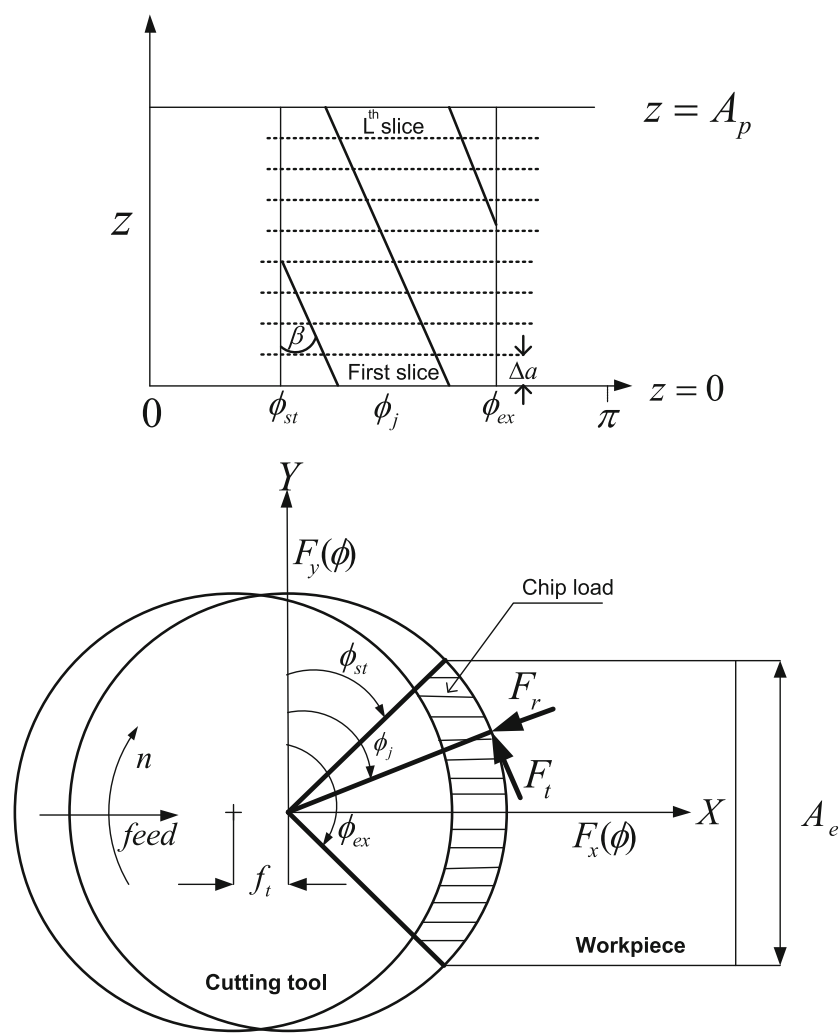

Fig. 4 Chip formation phenomenon in milling operation

angle of immersion. The tangential cutting force $\left(F_{\mathrm{t}}(\phi)\right)$, radial cutting force $\left(F_{\mathrm{r}}(\phi)\right)$, and axial cutting force $\left(F_{\mathrm{a}}(\phi)\right)$ are expressed as a function of the varying uncut chip area $(\Delta a h(\phi))$ and the edge contact length $(\Delta a)$ :

$F_{\mathrm{t}}(\phi)=\left[K_{\mathrm{tc}} h(\phi)+K_{\mathrm{te}}\right] \Delta a$

$F_{\mathrm{r}}(\phi)=\left[K_{\mathrm{rc}} h(\phi)+K_{\mathrm{re}}\right] \Delta a$

$F_{\mathrm{a}}(\phi)=\left[K_{\mathrm{ac}} h(\phi)+K_{\mathrm{ae}}\right] \Delta a$

where $K_{\mathrm{tc}}, K_{\mathrm{rc}}$, and $K_{\mathrm{ac}}$ are the cutting force coefficients contributed by the shearing action and $K_{\text {te }}$, $K_{\mathrm{re}}$, and $K_{\mathrm{ae}}$ are the edge constants in the tangential, radial, and axial directions, respectively. The milling cutting forces in the feed $(X)$, normal to feed $(Y)$, and axial $(Z)$ directions acting on the cutting tool are given by Eq. 6 :

$$
\begin{aligned}
& F_{x}(\phi)=-F_{\mathrm{t}} \cos \phi-F_{\mathrm{r}} \sin \phi \\
& F_{y}(\phi)=F_{\mathrm{t}} \sin \phi-F_{\mathrm{r}} \cos \phi \\
& F_{z}(\phi)=F_{\mathrm{a}} .
\end{aligned}
$$

The cutting forces are produced when the cutting tool is in the cutting zone

$$
F_{x}(\phi), F_{y}(\phi), F_{z}(\phi)>0 \quad \phi_{\mathrm{st}} \leq \phi \leq \phi_{\mathrm{ex}} .
$$


Here, $\phi_{\mathrm{st}}$ is the start angle and $\phi_{\mathrm{ex}}$ is the exit angle in the cutting zone which depends on the milling mode and radial depth of cut. The resultant cutting force acting on the cutting tool in the $X Y$ plane is expressed as

$F(\phi)=\sqrt{F_{x}(\phi)^{2}+F_{y}(\phi)^{2}}$ and $F=\max (F(\phi))$.

The cutting power and torque are calculated as

$T_{\mathrm{c}}(\phi)=\frac{D F_{\mathrm{t}}(\phi)}{2,000}$

$P_{\mathrm{c}}(\phi)=\frac{2 \pi n T_{\mathrm{c}}(\phi)}{60,000}$.

Here, $T_{\mathrm{c}}$ is the cutting torque in newton meter, $P_{\mathrm{c}}$ is the cutting power in kilowatt. The maximum values of cutting power and torque per revolution are used during the optimization analysis. The cutting power $\left(P_{\mathrm{c}}\right)$ and cutting torque $\left(T_{\mathrm{c}}\right)$ for the selected cutting conditions should not exceed the available machine tool spindle power and spindle torque.

\subsection{Stability of the milling process}

Poor selection of cutting conditions during process planning leads to unstable milling (chatter vibrations). Chatter vibrations are characterized by the chaotic relative motion between the cutting tool and the workpiece and by high fluctuations of cutting forces along the toolpath. Regenerative chatter is a function of the variation in chip thickness that occurs due to the vibrations in spindle/tool holder/cutting tool system. These vibrations are imprinted by the cutting tool tip on the workpiece and leave a wavy surface. The next flute of rotating cutting tool overcuts the wavy surface generated by the previous flute. This phenomenon is demonstrated in Fig. 5. This wavy surface varies the instantaneous chip thickness which modulates the cutting forces and cutting tool vibrations (i.e., a feedback mechanism is produced that leads to chatter vibrations). The variation of the chip thickness strongly depends on the phase difference between the wavy surface left by the previous flute and current cutting tool vibration. This phenomenon is illustrated in Fig. 6. If the relative phase is $0 \mathrm{deg}$, the dynamic chip thickness is also zero and leads to chatter-free milling. When the relative phase is $180 \mathrm{deg}$, the growing cutting forces and vibrations lead to high chatter vibrations.

For a given set of inputs, the border between chatter and chatter-free milling can be described in terms of the axial depth of cut as a function of spindle speed. The resulting border is presented in terms of a chart called the stability lobe diagram (SLD). The selection of cutting conditions from the SLD at the process

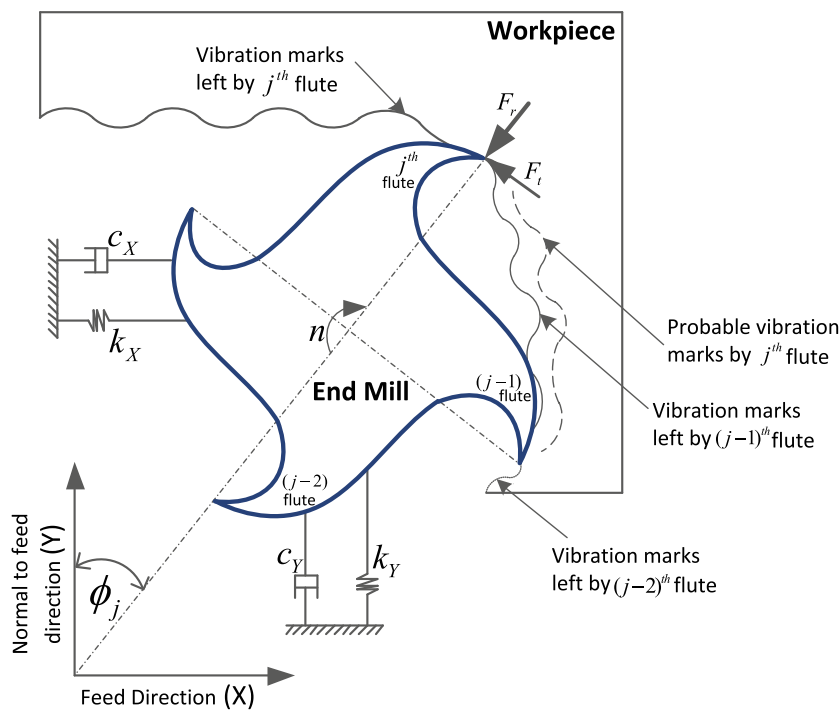

Fig. 5 Flexible cutting tool system, redrawn from [20]

planning stage ensures the stability during the actual cutting process. The algorithm for zero-order frequency domain solution developed by Altintas and Budak [20] is embedded in GA-OptMill to ensure stable (chatterfree) milling. The limiting value of the axial depth of cut is calculated by Eq. 10 .

$A_{\mathrm{plim}}=-\frac{2 \pi \Lambda_{R}}{N K_{\mathrm{tc}}}\left(1+\kappa^{2}\right)$

Here, $\kappa=\frac{\Lambda_{I}}{\Lambda_{R}}$, where $\Lambda_{R}$ and $\Lambda_{I}$ are the real and imaginary parts of the eigenvalue solution. $K_{\mathrm{tc}}$ is the tangential cutting force coefficient.

$\Lambda=-\frac{1}{2 a_{0}}\left(a_{1} \pm \sqrt{a_{1}^{2}-4 a_{0}}\right)$

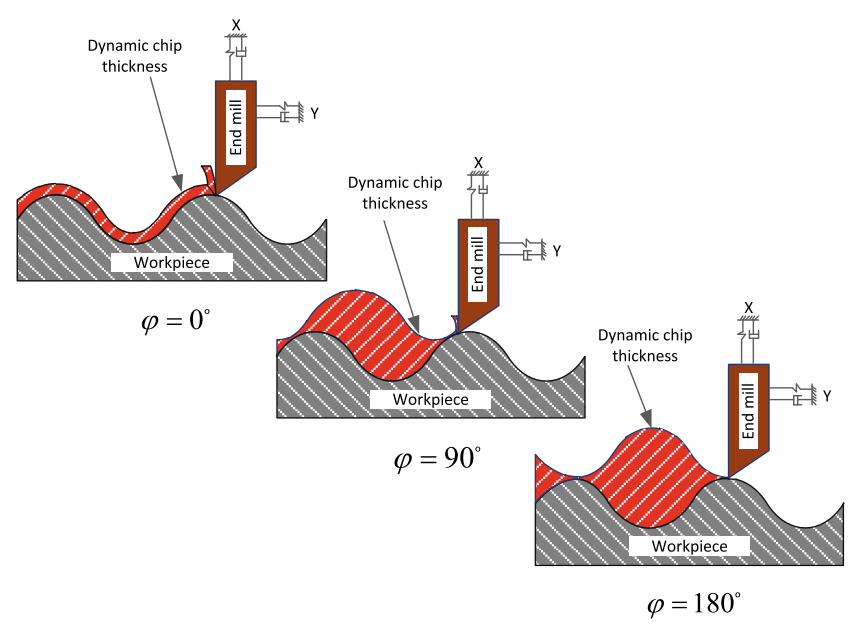

Fig. 6 Variation of chip thickness 
and

$a_{0}=\Phi_{\mathrm{xx}}(\omega) \Phi_{\mathrm{yy}}(\omega)\left(\alpha_{x x} \alpha_{y y}-\alpha_{x y} \alpha_{y x}\right)$

$a_{1}=\alpha_{x x} \Phi_{\mathrm{xx}}(\omega)+\alpha_{y y} \Phi_{\mathrm{yy}}(\omega)$.

Here, $\Phi_{\mathrm{xx}}$ and $\Phi_{\mathrm{yy}}$ are the frequency response functions measured in feed and normal to feed directions, respectively. $\alpha$ terms are the directional milling coefficients which depend on radial depth of cut and radial cutting force coefficient, $K_{\mathrm{rc}}$, and are given by

$\alpha_{x x}=\frac{1}{2}\left[\cos 2 \phi-2 K_{\mathrm{r}} \phi+K_{\mathrm{r}} \sin 2 \phi\right]_{\phi_{\mathrm{st}}}^{\phi_{\mathrm{ex}}}$

$\alpha_{x y}=\frac{1}{2}\left[-\sin 2 \phi-2 \phi+K_{\mathrm{r}} \cos 2 \phi\right]_{\phi_{\mathrm{st}}}^{\phi_{\mathrm{ex}}}$

$\alpha_{y x}=\frac{1}{2}\left[-\sin 2 \phi+2 \phi+K_{\mathrm{r}} \cos 2 \phi\right]_{\phi_{\mathrm{st}}}^{\phi_{\mathrm{ex}}}$

$\alpha_{y y}=\frac{1}{2}\left[-\cos 2 \phi-2 K_{\mathrm{r}} \phi-K_{\mathrm{r}} \sin 2 \phi\right]_{\phi_{\mathrm{st}}}^{\phi_{\mathrm{ex}}}$.

Spindle speed is given by

$n=\frac{60 \omega_{c}}{N\left(\pi-2 \tan ^{-1} \kappa+2 s \pi\right)}$

where $s$ is the number of lobes generated between the tooth periods and $\omega_{\mathrm{c}}$ is the chatter frequency. Spindle speed and axial depth of cut have a complex nonlinear relationship for a given radial depth of cut. For a given set of inputs, the limiting value of the axial depth of cut at desired spindle speed is calculated at a given radial depth of cut as described by the developed module for stable limits prediction as shown in Fig. 7. The various inputs for the stability lobe diagram generation module are cutting tool tip frequency response function in the feed and normal to the feed directions, cutting force coefficients, cutting tool diameter and number of flutes, and radial depth of cut. The effect of feed rate on the stability limit is minimal at high-speed milling [21].

The limiting value of stable axial depth of cut, at selected spindle speed and radial depth of cut, must be higher than the selected axial depth of cut in order to ensure chatter-free milling. More details of stability limit prediction theory can be found in [20,24].

\subsection{Cutting tool bending stress}

The bending stress is produced in the cutting tool due to the action of cutting forces on the cutting tool during the milling process as shown in Fig. 8. The bending moment produced due to cutting forces is given by Eq. 15 [25]:

$M=F\left(L-\frac{A_{\mathrm{p}}}{3}\right)$.

Here, $L$ is the overhang length of the cutting tool and is given by

$L=L_{\text {tool }}-L_{\text {fix }}$.

The bending stress developed in the cutting tool due to the bending moment is given by Eq. 17:

$\sigma_{\mathrm{b}}=\frac{M D_{\mathrm{c}}}{2 I}$.

Here, $I$ and $D_{\mathrm{c}}$ are the area moment of inertia of the cutting tool cross section and equivalent diameter, respectively, and are calculated by the following equations:

$D_{\mathrm{c}}=0.8 D$

$I=\frac{\pi D_{\mathrm{c}}^{4}}{64}$.

The developed bending stress for selected cutting conditions should not exceed the yield stress limit of the cutting tool material. This avoids breakage of the cutting tool and avoids unnecessary delay during the machining process.

\subsection{Deflection of cutting tool}

The cutting tool is deflected under the action of the cutting forces. Excessive static deflection due to high cutting forces may lead to workpiece tolerance violation thus significantly influence the part quality, cutting
Fig. 7 Module for the prediction of stability limits

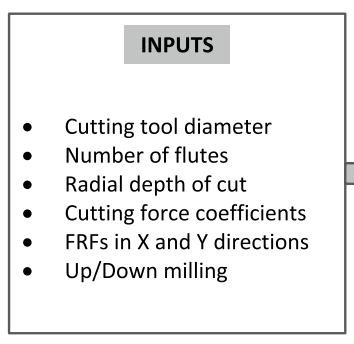

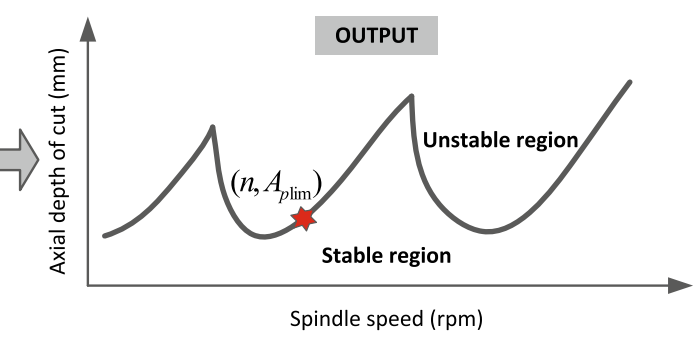




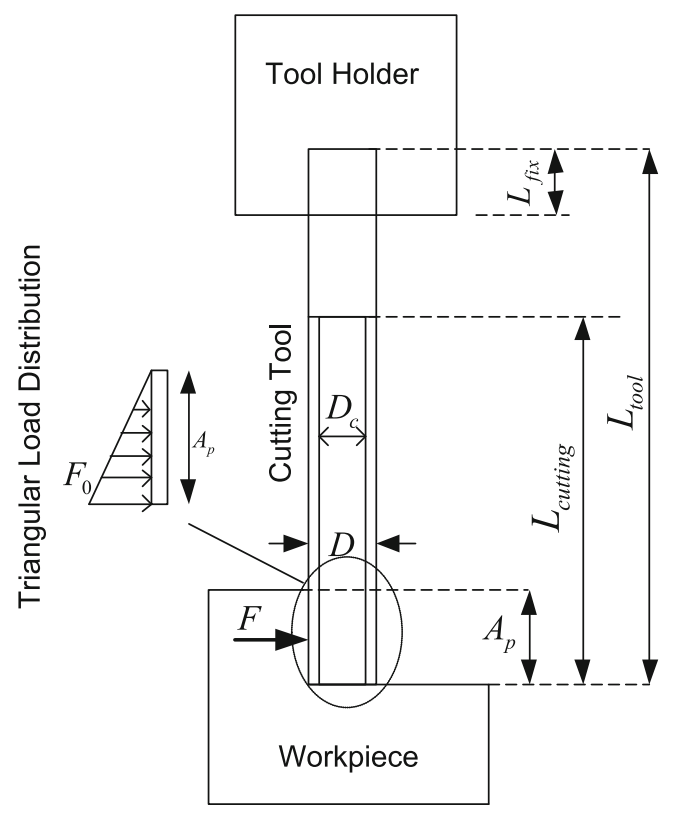

Fig. 8 Bending moment acting on the cutting tool

tool working life, and overall productivity. It is important to control cutting tool deflections within the allowed tolerance limits by right selection of cutting conditions. Using a cantilever beam model, the cutting tool deflection is computed by Eq. 20 [26]:

$\delta=\frac{1}{E I}\left[\frac{F_{0} A_{\mathrm{p}}\left(L-\frac{A_{\mathrm{p}}}{3}\right) L^{2}}{4}-\frac{F_{0} A_{\mathrm{p}} L^{3}}{12}+\frac{F_{0} A_{\mathrm{p}}{ }^{4}}{120}\right]$.

Here, $E$ is Young's modulus and $F_{0}$ is the cutting load per unit length (in newtons per millimeter) and is calculated by

$F_{0}=\frac{2 F_{\text {ymax }}}{A_{\mathrm{p}}}$.

Cutting tool deflections developed for selected cutting conditions must be within permissible tolerance limits.

\subsection{Clamping load limits}

In production floors, clamping load is decided based on the stiffness of the workpiece in order to avoid the unnecessary workpiece deformations during milling. Higher cutting forces encountered during the milling cause the workpiece displacement if the clamping forces are not sufficient enough. The resulting cutting forces generated for selected cutting conditions must be less than the applied clamping load to avoid workpiece rigid body displacements.

\section{Genetic algorithm optimization}

In this section, the developed GA-based optimization for the minimization of pocket machining time is presented. Details of GA initialization, encoding of cutting conditions, and various GA operators used in the developed optimization system are explained.

\subsection{GA initialization}

\subsubsection{Encoding of design variables}

For a given set of inputs, lower and upped bounds of the cutting conditions are defined. Radial depth of cut ranges lies from 0 to the cutting tool diameter, and axial depth of cut lies from 0 to minimum of cutting length of the tool or depth of the pocket. Spindle speed and feed rate ranges are selected from the machine tool system specifications. The user also has the flexibility to select these bounds depending upon the requirements and application.

The values of the design variables ( $X_{i}$ 's) are encoded with a binary-coded string, composed of zeros(0) and ones (1), which is called a chromosome [25]. For the present work, design variables $\left(X_{i}^{\prime}\right.$ 's) are spindle speed $(n)$, axial depth of cut $\left(A_{\mathrm{p}}\right)$, radial depth of cut $\left(A_{\mathrm{e}}\right)$, and feed rate $\left(f_{\mathrm{t}}\right)$. A segment of each design variable is assigned with six bits (also called genes). The length of each segment (also called "bitsize") is selected based on the accuracy required for the solution. As illustrated in Fig. 9, each cutting condition is a quarter segment of a coded binary string and represents a percentage value of the range of the cutting conditions which is given by Eq. 22:

$X=\left(\frac{X_{\max }-X_{\min }}{63}\right) Y+X_{\min }$.

Here, $Y$ is the decoded value (decimal value) of the respected segment of the chromosome, $X$ is the mapped value of the cutting condition, and $X_{\min }$ and $X_{\max }$ are the lower and upper bounds of the corresponding cutting condition, respectively; 63 is the decimal value of "111111." For example, the spindle speed range is 10,000-20,000 rpm and the decoded value of the spindle speed segment is 53 (conversion of " 110101 " to a

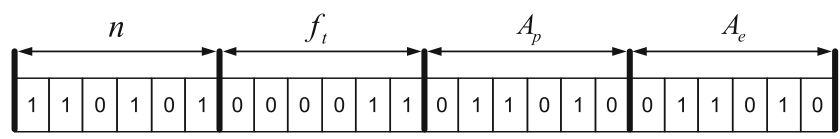

Fig. 9 Binary-coded string (chromosome structure) 
decimal value). The mapped value of the spindle speed will be $18,412 \mathrm{rpm}$. The same procedure is adopted to map the values of other cutting conditions. The developed program has the flexibility to alter the length of the chromosome depending upon the number of design variables and bits assigned to each variable.

\subsubsection{Initial population}

The initial population is created by randomly generating the chromosomes. The feasibility of each chromo-

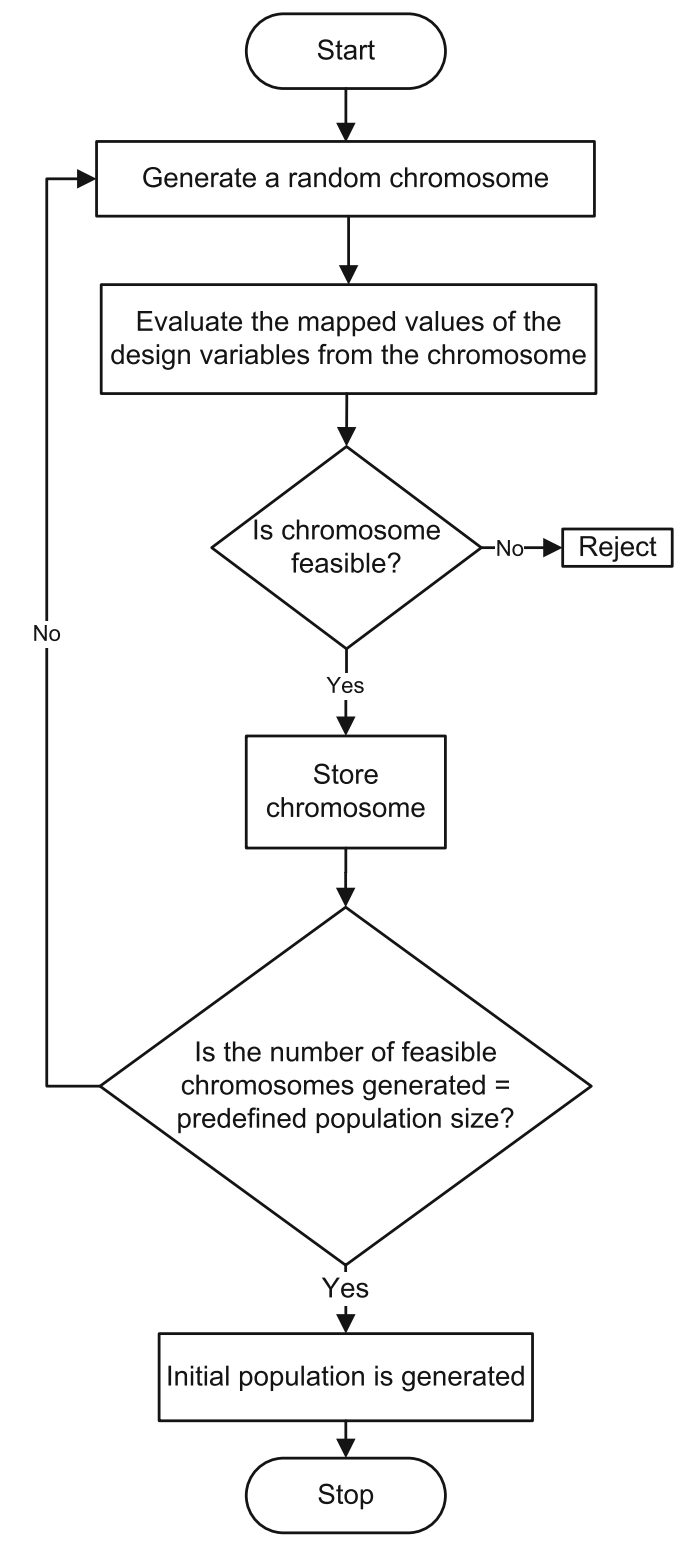

Fig. 10 Algorithm to generate an initial population of chromosomes some is checked with various constraints presented in Section 3. It is important to mention that the feasible operational limits for all design variables are already taken into account during the selection of their bounds at GA initialization for better GA performance. Feasible chromosomes (chromosomes which respect all the constraints) are solutions to the optimization problem which may or may not be optimal. The minimization problem "pocket milling time" is converted to a maximization problem "fitness value." Fitness value $(f)$ of a given feasible chromosome is calculated as

$$
f=\frac{1}{1+T_{\mathrm{mac}}} .
$$

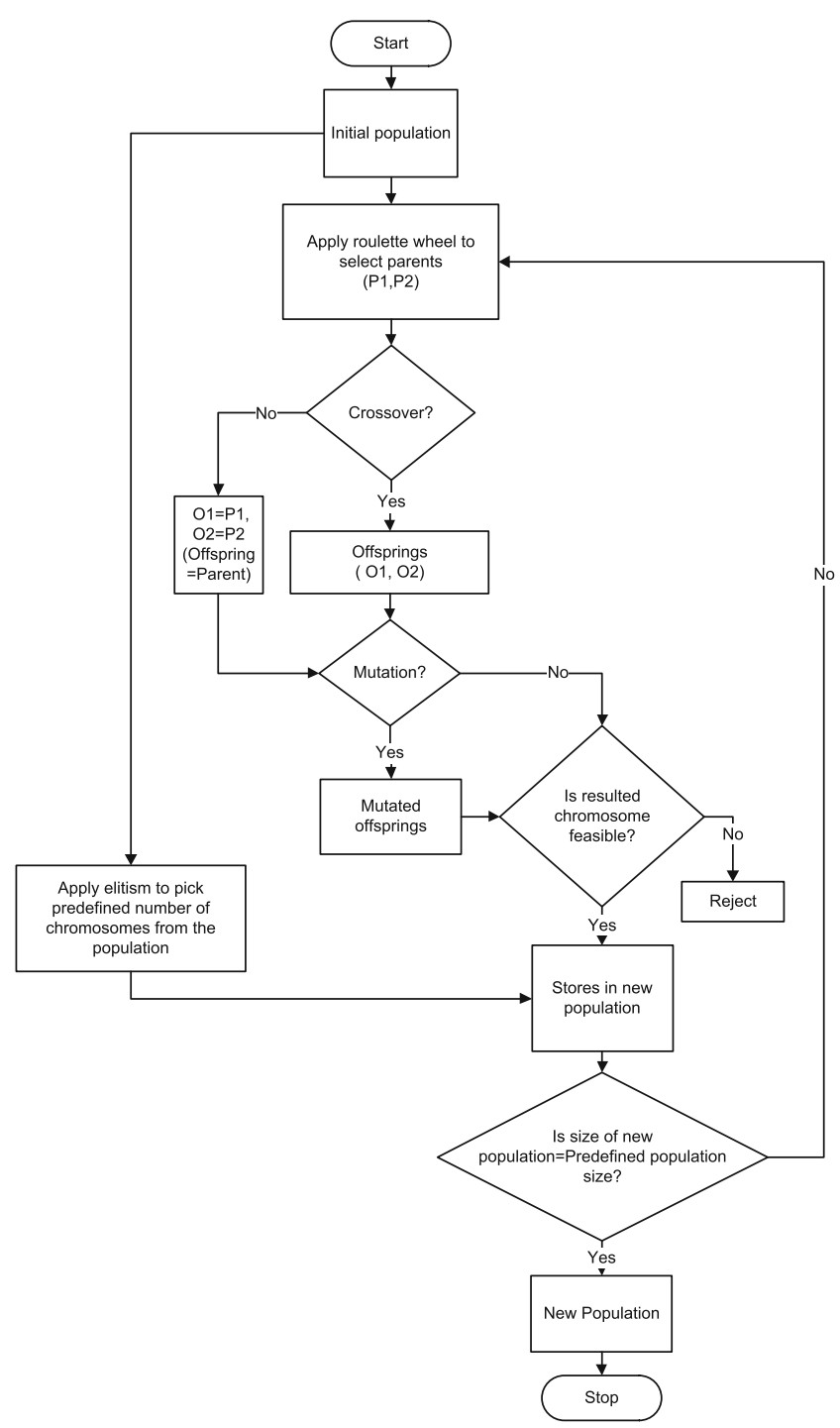

Fig. 11 Algorithm to generate new population from the previous population 


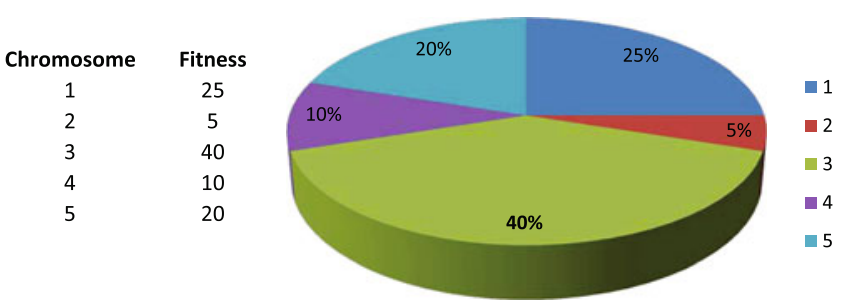

Fig. 12 Roulette wheel as reproduction operator

Here, $T_{\operatorname{mac}}$ is the machining time (from Eq. 2) and is given by

$$
\begin{aligned}
T_{\mathrm{mac}}= & \operatorname{ceil}\left(\frac{W_{\mathrm{p}}-2 D}{A_{\mathrm{e}}}\right) \\
& \times \operatorname{ceil}\left(\frac{D_{\mathrm{p}}}{A_{\mathrm{p}}}\right)\left[\frac{n N f_{\mathrm{t}}}{A}+\frac{L_{\mathrm{p}}-2 D}{n N f_{\mathrm{t}}}\right] 60 .
\end{aligned}
$$

The steps involved in generating the initial population for GA initiation are presented in Fig. 10.

\subsection{GA operators}

After creating the initial population, the next generation (new population) is produced using various GA operators, namely, reproduction, crossover, and mutation. The steps involved for creating the generation are presented in Fig. 11. The GA operators used in the developed optimization system are explained in subsequent subsections:

\subsubsection{Reproduction}

Reproduction selects the above-average chromosomes from the current population and makes the mating pool in a probabilistic manner. The $i$ th chromosome in the population is selected with a probability proportional

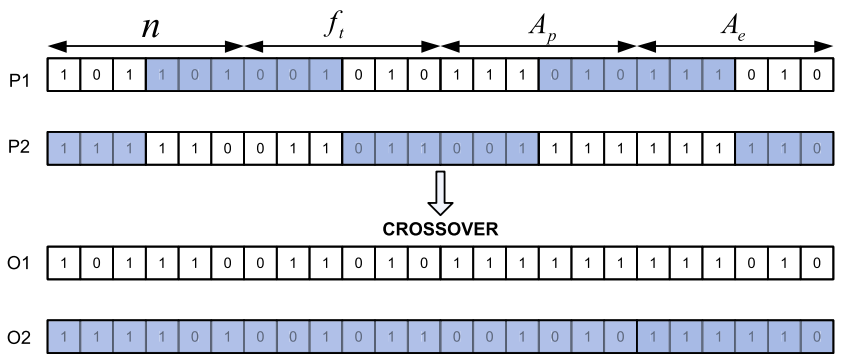

Fig. 13 Crossover operator

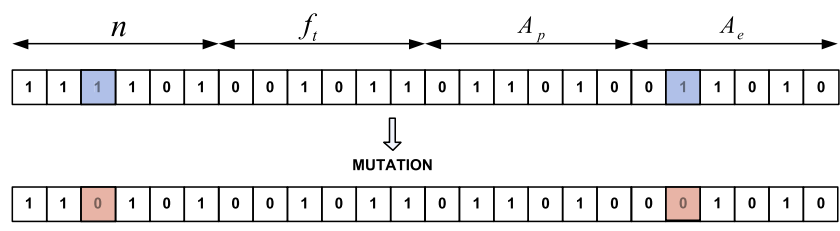

Mutation sites

Fig. 14 Mutation operator

to its fitness value, $f_{i}$. The probability $p_{i}$ for selecting the $i$ th chromosome is given by Eq. 25:

$p_{i}=\frac{f_{i}}{\sum_{j=1}^{P_{\text {size }}} f_{j}}$.

Here, $P_{\text {size }}$ is the number of chromosomes in the population (also called population size). A roulette wheel selection is used as a reproduction operator. A roulette wheel is created and divided into slots equal to the population size. The width of the slot is proportional to the fitness value of the chromosome. For an example, a roulette wheel for five chromosomes is given in Fig. 12. A slot width for the first chromosome is calculated as $25 /(25+5+40+10+20)$. It is obvious from the roulette wheel selection that chromosomes

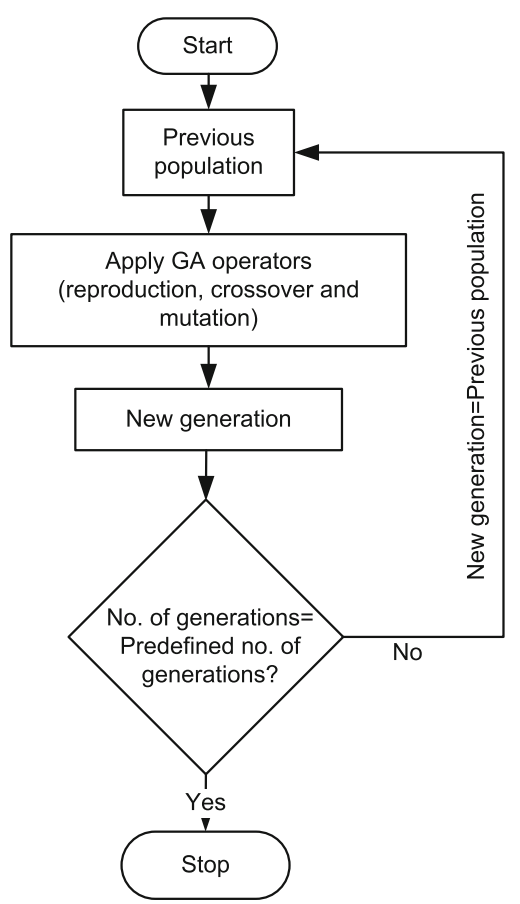

Fig. 15 Algorithm for iteration loop for GA analysis 
Table 1 Specifications of the cutting tool

\begin{tabular}{lllll}
\hline$D(\mathrm{~mm})$ & $\beta(\mathrm{deg})$ & $N$ & $L_{\text {tool }}(\mathrm{mm})$ & $L_{\text {cutting }}(\mathrm{mm})$ \\
\hline 16 & 40 & 2 & 92 & 26
\end{tabular}

with higher fitness values have a greater chance of being selected for the mating pool than the chromosomes with a lesser fitness value. In order to ensure that better chromosomes from the previous population should not be lost during reproduction, elitism is also used. In elitism, a fixed number of chromosomes (with better fitness value) is taken from the previous population and transferred without any change to the new population.

\subsubsection{Crossover}

Two different chromosomes (now called parents) are selected from the roulette wheel to generate two offsprings (also called children). The multipoint crossover operator is applied in the present work. A predefined crossover probability $\left(C_{\text {prob}}\right)$ is set (usually a high value, $60-100 \%$ ). An example of a crossover operator used for the present work is shown in Fig. 13. Parents $\mathrm{P} 1$ and $\mathrm{P} 2$ are selected for the crossover, and the crossover site is found by generating a random number from 1 to 5. As an example, multipoint crossover with random crossover site " 3 " is shown in Fig. 13. P1 and $\mathrm{P} 2$ are interchanged with their alleles ( 0 and 1$)$ between crossover sites to give birth to offsprings, $\mathrm{O} 1$ and $\mathrm{O} 2$.

\subsubsection{Mutation}

As the optimization problem is highly nonlinear, a mutation operator is used to prevent the GA solution falling into a local minima/maxima. A predefined mutation probability ( $M_{\mathrm{prob}}$ ) is set for GA analysis (usually a small value, $1-5 \%$ ). During mutation, the allele of the gene is interchanged, zero (0) is changed with one (1) and vice versa. In the present work, for a given chromosome, each gene has an independent chance, with predefined mutation probability, to mutate. The mutation operator used for the developed system is shown in Fig. 14. In this example, 3 and " 20 " are the mutation sites. Only feasible mutated offsprings,

Table 2 Experimentally identified cutting force coefficients

\begin{tabular}{llllll}
\hline $\begin{array}{l}K_{\mathrm{tc}} \\
\left(\mathrm{N} / \mathrm{mm}^{2}\right)\end{array}$ & $\begin{array}{l}K_{\mathrm{rc}} \\
\left(\mathrm{N} / \mathrm{mm}^{2}\right)\end{array}$ & $\begin{array}{l}K_{\mathrm{ac}} \\
\left(\mathrm{N} / \mathrm{mm}^{2}\right)\end{array}$ & $\begin{array}{l}K_{\mathrm{te}} \\
(\mathrm{N} / \mathrm{mm})\end{array}$ & $\begin{array}{l}K_{\mathrm{re}} \\
(\mathrm{N} / \mathrm{mm})\end{array}$ & $\begin{array}{l}K_{\mathrm{ae}} \\
(\mathrm{N} / \mathrm{mm})\end{array}$ \\
\hline 681 & 86 & 218 & 12 & 19 & 2 \\
\hline
\end{tabular}
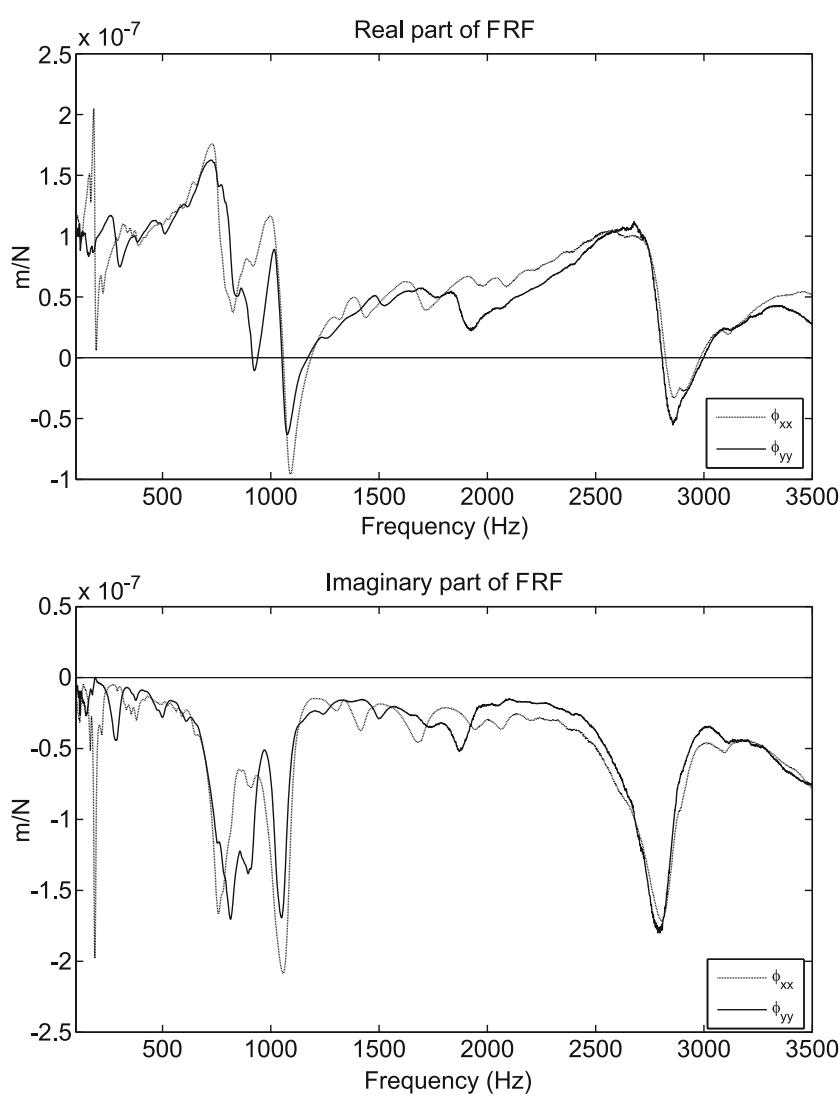

Fig. 16 Experimentally measured frequency response function

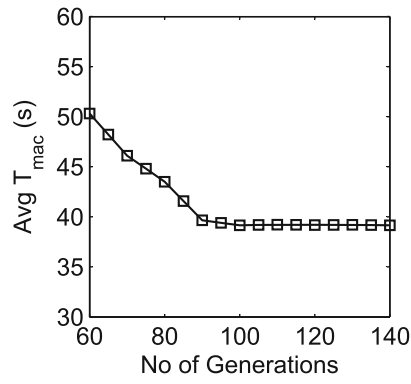

(a)

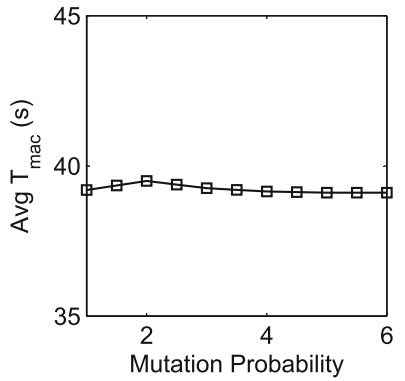

(c)

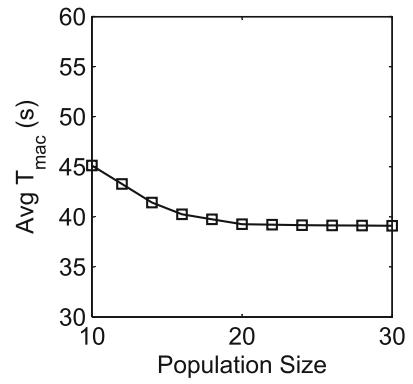

(b)

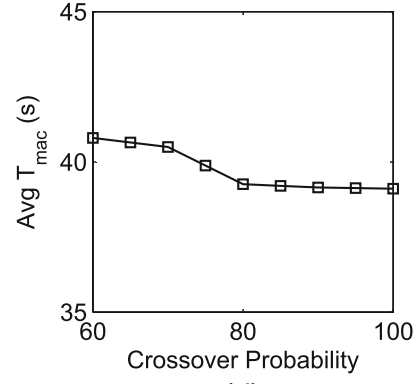

(d)
Fig. 17 Effect of GA parameters on machining time 
Fig. 18 Convergence of cutting conditions

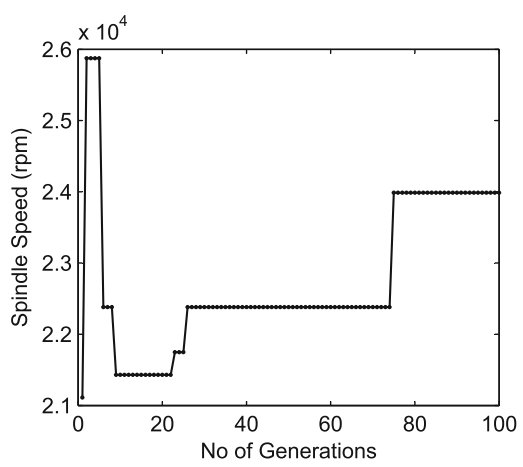

(a)

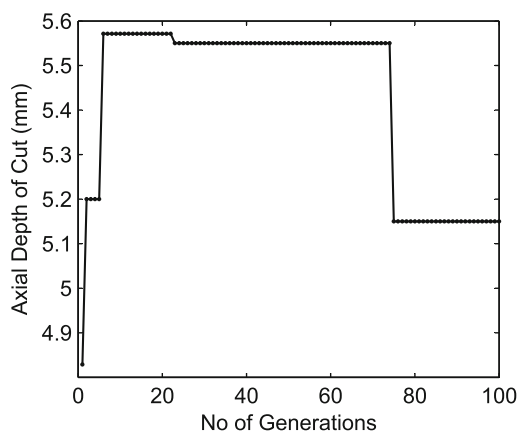

(c)

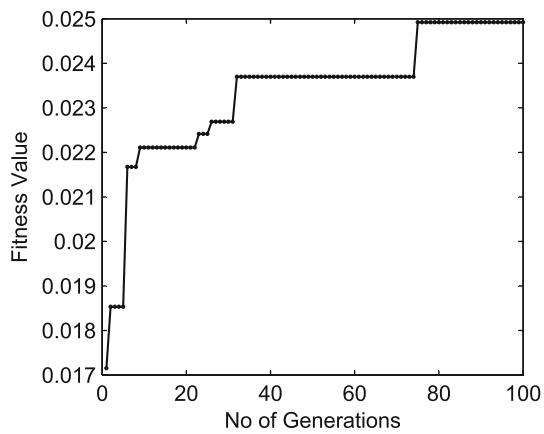

(e)

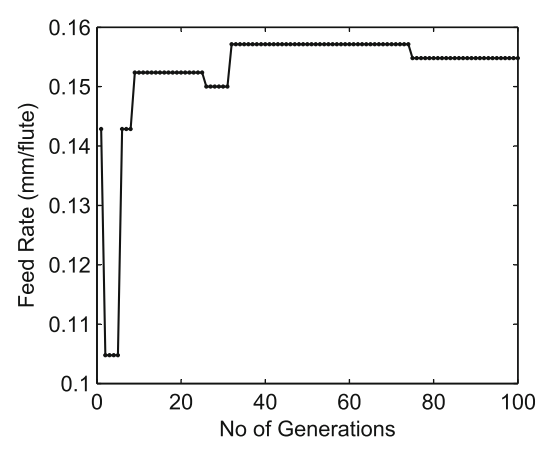

(b)

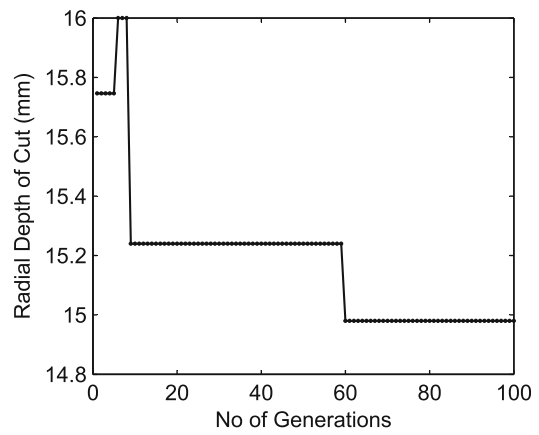

(d)

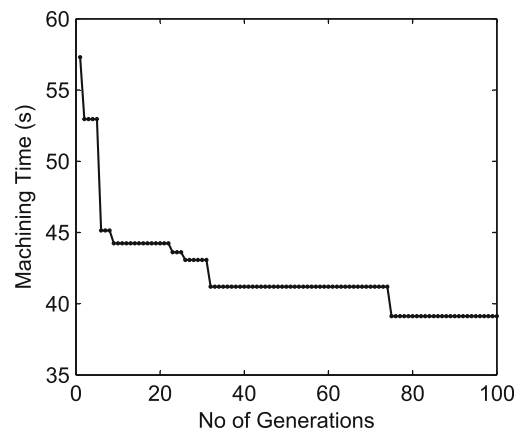

(f) defined as the feasible chromosome, are taken in the next generation.

\subsection{GA iteration loop}

Using the above-defined GA operators, the next generation (new population) is produced. GA analysis is an iterative loop and will continue until the predefined generation size $\left(G_{\text {size }}\right)$ is reached. The $G_{\text {size }}$ is chosen based on the convergence of the optimization problem. The steps involved are presented in Fig. 15.

\section{Implementation and experimental validation}

The capabilities of the developed GA-OptMill system are demonstrated for the optimal selection of cutting

Table 3 Optimal cutting conditions for different pockets

\begin{tabular}{|c|c|c|c|c|c|c|c|c|c|c|}
\hline$L_{\mathrm{p}} / W_{\mathrm{p}} / D_{\mathrm{p}}$ & $n / f_{\mathrm{t}} / A_{\mathrm{p}} / A_{\mathrm{e}}$ & norp/noap/nop & $A_{\mathrm{p}}^{\prime} / A_{\mathrm{e}}^{\prime}$ & $T_{\mathrm{mac}}$ & $P_{\mathrm{c}}$ & $T_{\mathrm{c}}$ & $\sigma_{\mathrm{b}}$ & $\delta$ & $A_{\text {plim }}$ & $F_{\text {clamp }}$ \\
\hline $150 / 150 / 25$ & 23,986/0.1548/5/14.98 & $8 / 5 / 40$ & $5 / 14.75$ & 39.12 & 11.67 & 4.6 & 174.7 & 0.07 & 11.1 & 621.8 \\
\hline $100 / 160 / 60$ & $13,175 / 0.1190 / 22.66 / 8.63$ & $15 / 3 / 45$ & $20 / 8.53$ & 59.02 & 11.2 & 8.1 & 256 & 0.06 & 24.8 & 997 \\
\hline $170 / 100 / 20$ & $16,667 / 0.1667 / 6.67 / 14.73$ & $5 / 3 / 15$ & $6.67 / 13.60$ & 22.63 & 11.47 & 6.57 & 242.1 & 0.09 & 22.5 & 870.8 \\
\hline $140 / 140 / 38$ & $12,858 / 0.1810 / 22.29 / 6.10$ & $18 / 2 / 36$ & $19 / 6$ & 50.68 & 11.15 & 8.26 & 270.2 & 0.05 & 33.2 & $1,045.7$ \\
\hline
\end{tabular}


conditions for different pocket sizes with real input data of machine tool and workpiece system. The automatically identified optimal cutting conditions are also verified experimentally.

\subsection{Input definition}

The specifications of the used cutting tool are presented in Table 1. Workpiece material is Certal (AlZnMgCu0.5/EN AW-7072). Experimentally measured cutting force coefficients for the given cutting tool and workpiece material combination are presented in Table 2. A five-axis vertical machine tool C.B.Ferrari A152 is used for experimental validation. The machine tool is capable of rotational speeds up to $30,000 \mathrm{rpm}$, axis acceleration up to $5 \mathrm{~m} / \mathrm{s}^{2}$, and feed speeds up to $50 \mathrm{~m} / \mathrm{min}$. The rated power of the spindle is $12 \mathrm{~kW}$ (constant power curve in the desired range of spindle speed). Frequency response functions of the specified machine tool/spindle/tool holder/cutting tool system are measured at the cutting tool tip with hammer impacts. The frequency response functions in the feed and normal to feed directions are presented in Fig. 16. The clamping load limit is defined as $1,500 \mathrm{~N}$, allowable cutting tool deflection is fixed as $0.15 \mathrm{~mm}$, and permissible bending stress is taken as 2,683 $\mathrm{MPa}$. The favorable milling mode is selected as up-milling.

\subsection{Tuning of optimization system}

The various GA parameters (population size $\left(P_{\text {size }}\right)$, crossover probability $\left(C_{\text {prob }}\right)$, mutation probability $\left(M_{\text {prob }}\right)$, and generation size $\left.\left(G_{\text {size }}\right)\right)$ are tuned by studying their influence on pocket milling time. Simulations are run by varying each GA parameter and keeping the others constant. For each variation, two simulations are run and the average milling time is calculated. Convergence analysis for different GA parameters is performed for pocket size $150 \times 150 \times 25$. The bounds of spindle speed is $10,000-30,000 \mathrm{rpm}$, feed rate is $0.05-$ $0.2 \mathrm{~mm} / \mathrm{rev}$-flute, radial depth of cut is $0-16 \mathrm{~mm}$, and axial depth of cut is $0-25 \mathrm{~mm}$; these are selected for GA initialization. The convergence results for different values of generation size and population size are presented in Fig. 17a, b, respectively. Based on convergence results, a generation size $\left(G_{\text {size }}\right)$ of 100 and a population size $\left(P_{\text {size }}\right)$ of 20 is selected. It is important to mention that increasing the values of $G_{\text {size }}$ and $P_{\text {size }}$ significantly increases the computational time so their proper selection is necessary. Crossover probability is set as $90 \%$, and the results of the convergence are
Fig. 19 Experimental setup to validate the developed system

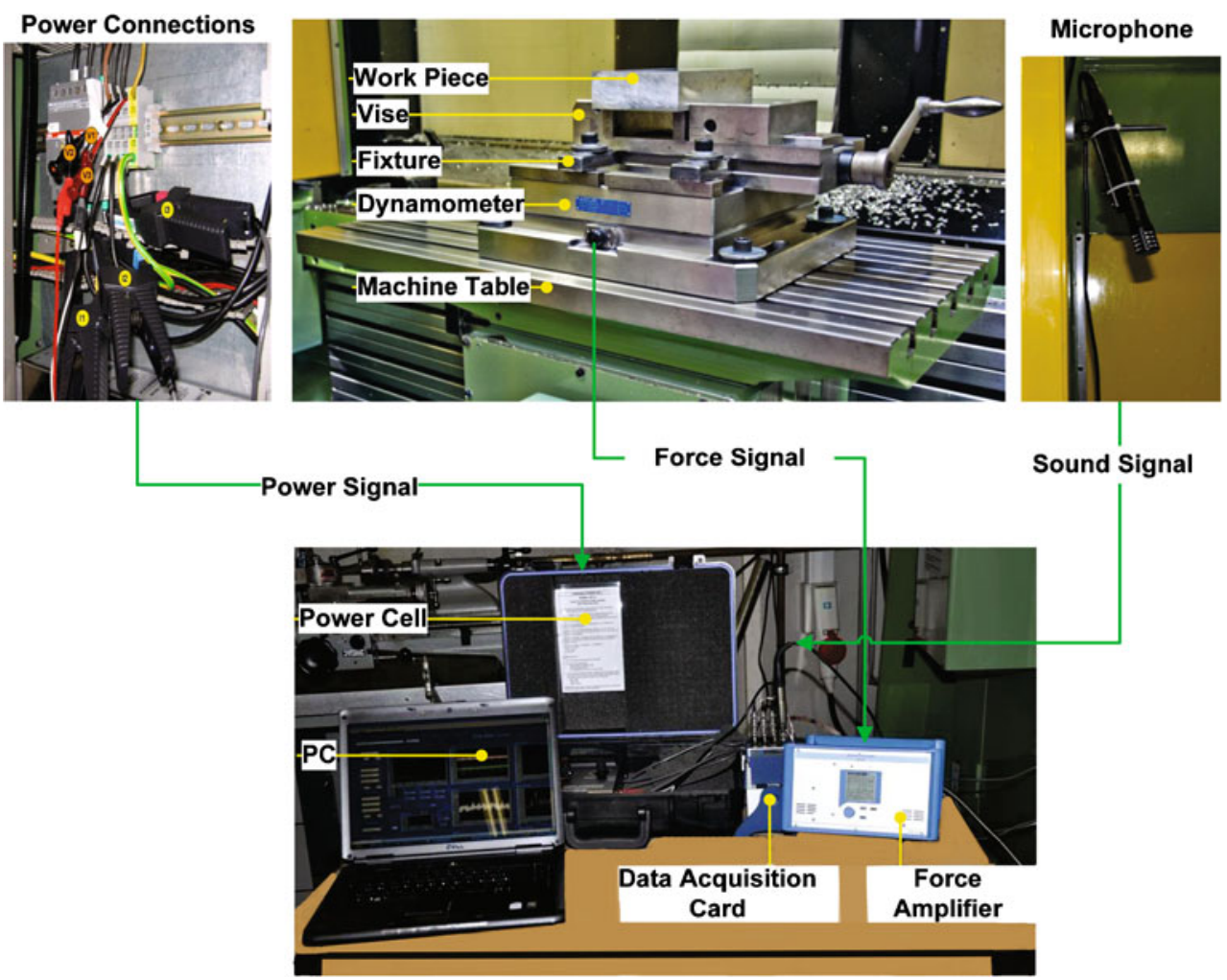


presented in Fig. 17d. Mutation probability has only a small influence on the optimal machining time as presented in Fig. 17c, and its value is set as $4 \%$. Elitism size of 2 is used during the optimization analysis.

\subsection{Simulation results}

The GA-OptMill system is implemented to select the optimal cutting conditions for pockets with different sizes. Convergence results of GA analysis for pocket $150 \times 150 \times 25$ are presented in Fig. 18. Figure $18 \mathrm{a}-\mathrm{d}$ presents the values of spindle speed, feed rate, axial depth of cut, and radial depth of cut with number of generations, respectively. The convergence results of fitness values and machining time are presented in Fig. 18e, f.

The optimal values of axial and radial depths of cut are postprocessed to distribute evenly by maintaining
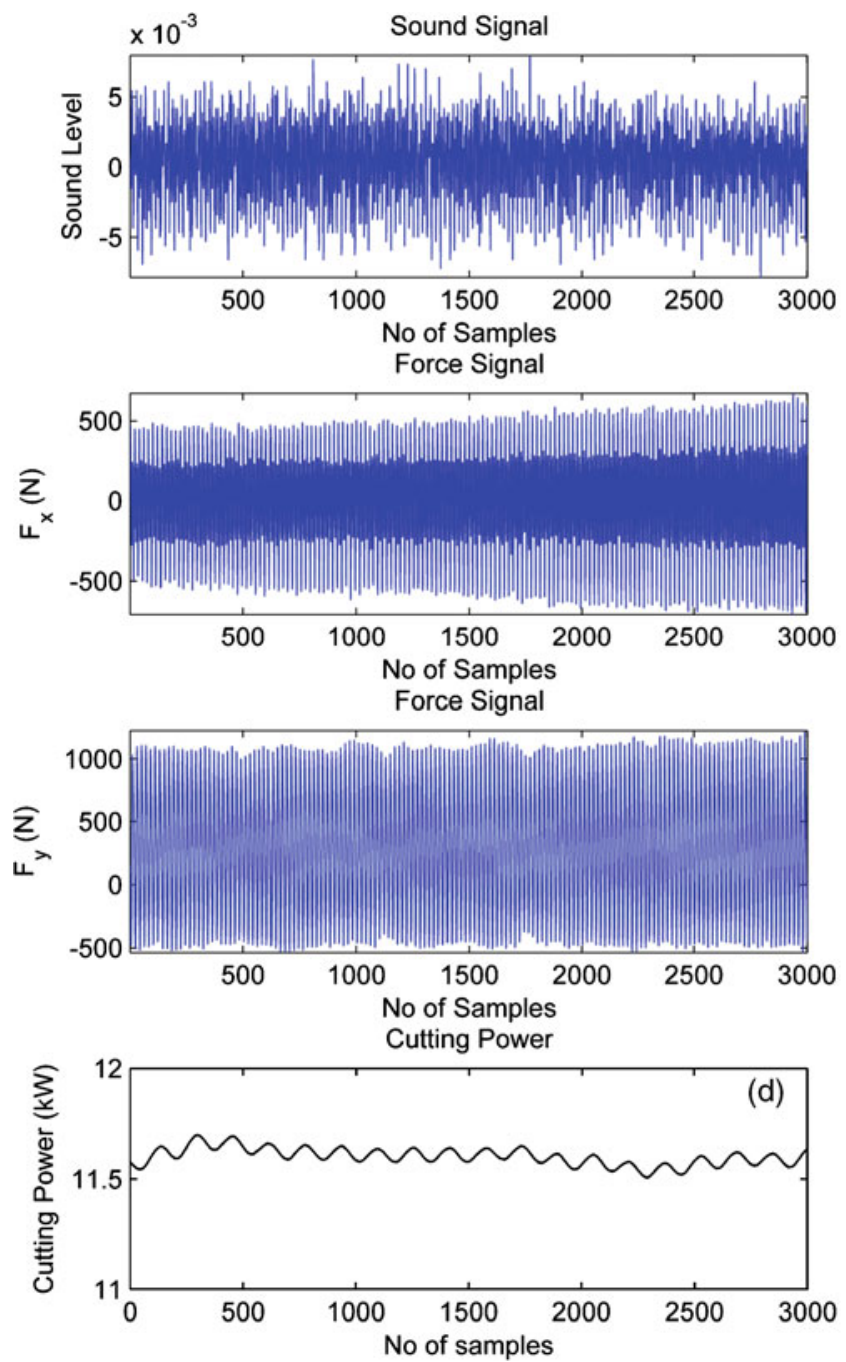

(b)

(c)

(a)
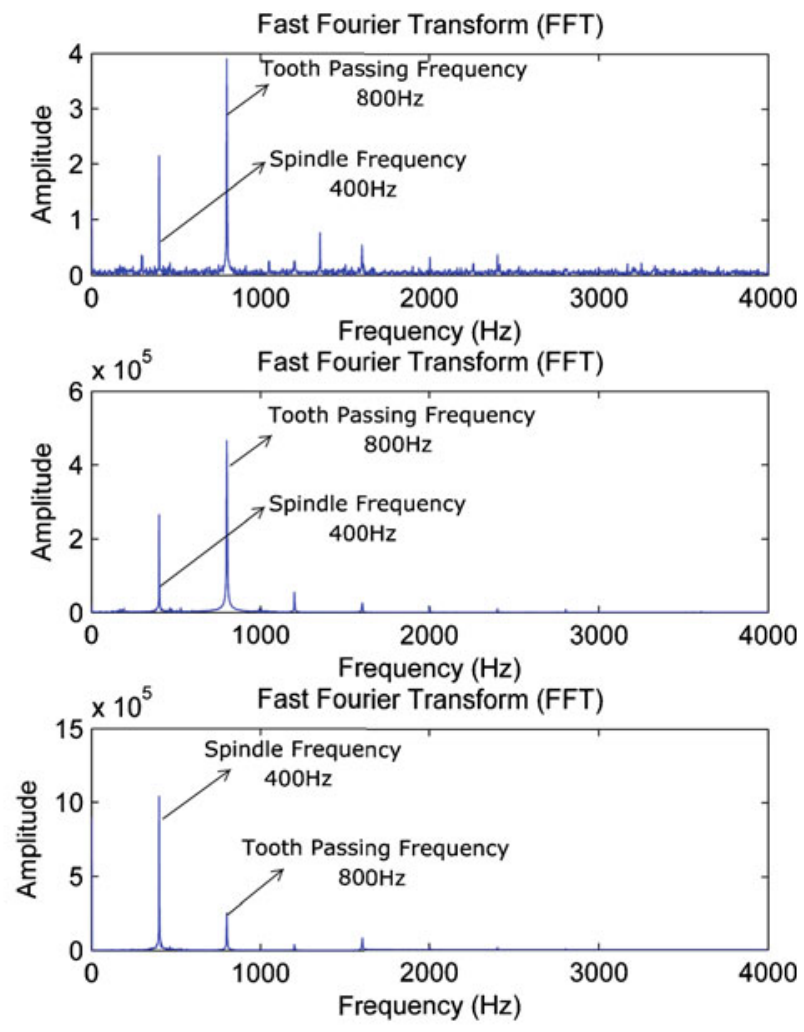

1. Stable Cutting: No chatter frequency peak in the frequency spectrum of cutting forces and cutting sound signal

2. Cutting power is below $12 \mathrm{~kW}$

Fig. 20 Experimental results 
The simulation results for different pocket sizes are presented in Table 3. The values of all the constraints for selected cutting conditions are also presented. It proves that optimal cutting conditions respect the permissible limits of the constraints. The optimal values of cutting conditions, corresponding number of passes, and postprocessed values of axial and radial depths of cut are also presented in Table 3. The first slot pass is inevitable. Each pocket is milled with selected cutting conditions. For example, pocket $150 \times 150 \times 25$ is machined with $14.75 \mathrm{~mm}$ of radial depth of cut (eight radial passes per axial pass) and $5 \mathrm{~mm}$ of axial depth of cut (five axial passes in total). The corresponding values of spindle speed and feed rate are $23,986 \mathrm{rpm}$ and $0.1548 \mathrm{~mm} / \mathrm{rev}$-flute, respectively. The optimal cutting conditions selected from developed optimization system are also verified experimentally.

\subsection{Experimental validation}

Experimental setup used for validation purpose is shown in Fig. 19. Cutting forces developed during the milling process are measured with table-type force dynamometer (Kistler 9255B) and corresponding

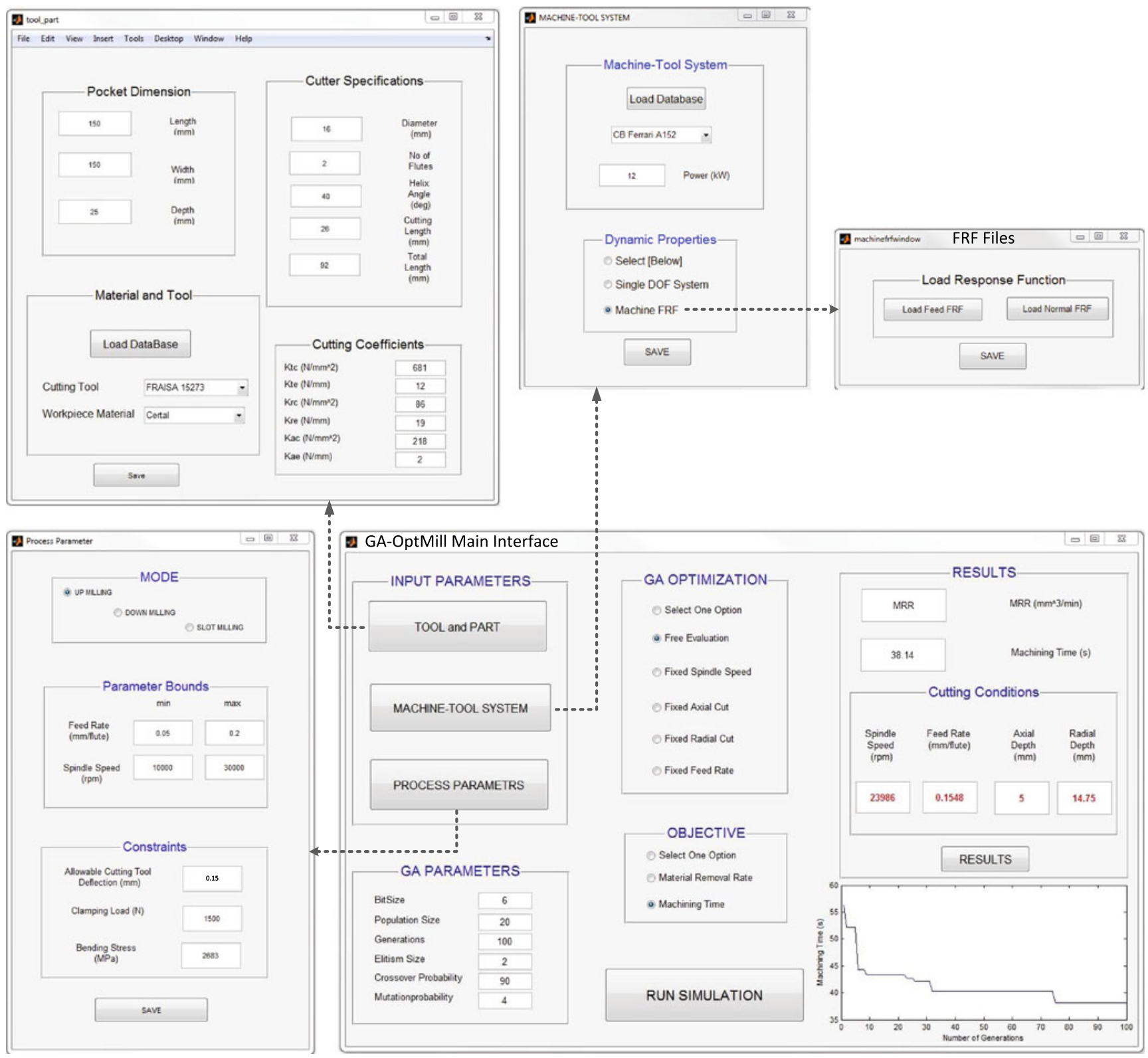

Fig. 21 GA-OptMill system: graphical user interface 
amplifier (Kistler 5070A10100). Cutting sound during milling is recorded with Shure microphone (PG18). Spindle power is measured with a power cell (PPC3). Spindle speed during the experiment is $24,000 \mathrm{rpm}$. Sound signal, cutting force signal in feed, and normal to feed direction collected during a single pass are demonstrated in Fig. 20a-c. The corresponding fast Fourier transform of sound and force signals are also presented. It is evident that cutting conditions are stable (chatter free) since there is no frequency other than the spindle frequency, tooth passing frequency, and their harmonics [27]. Measured cutting power is presented in Fig. 20d which is below the permissible limit of available power of $12 \mathrm{~kW}$.

\section{Scope for industrial implementation}

The developed graphical user interface for GAOptMill system is shown in Fig. 21. GA-OptMill has also the flexibility to perform the optimization analysis by keeping one of the cutting conditions constant during the simulation based on user requirements and application. GA-OptMill can be integrated directly in the current CAD/CAM packages or can be used as a PCbased stand-alone application for the selection of optimal cutting conditions at process planning stage. GAOptMill is very appealing for overall increase in the productivity by avoiding repercussions due to wrong selection of cutting conditions and simultaneously achieving the minimum pocket milling time.

\section{Conclusion and future research}

In the present work, a genetic algorithm-based optimization system is developed to automate the selection of the cutting conditions for the minimization of pocket milling time. The cutting conditions, spindle speed, feed rate, and axial and radial depth of cut, are encoded in a chromosome with binary bit strings. The feasibility of every chromosomes is checked with practical constraints encountered in high-speed milling such as the operational limits of spindle speed and feed rate, available spindle power and spindle torque of the machine tool, permissible bending stress and deflection of the cutting tool, and allowed clamping load for the workpiece system. Chatter vibration due to the dynamic interaction of machine tool/spindle/tool holder/cutting tool and the workpiece system is also considered as a constraint. Various GA operators, such as roulette wheel selection, elitism, multipoint crossover, and mutation, are implemented to process the chromosomes of previous populations to produce further generations. The developed GA-OptMill system is applied to identify optimal cutting conditions for different pockets and has been validated experimentally. The experimental validation proves the accuracy of the developed optimization system. GA-OptMill is very appealing for direct industrial implementation for optimal selection of cutting conditions at process planning stage to achieve higher productivity.

Though the present work is a significant step toward the optimal selection of cutting conditions at process planning stage, it is limited to simple pockets with simple shapes and linear toolpaths. In the future studies, it would be interesting to investigate and enhance the capabilities of the developed system for pockets with complex toolpaths. In these cases, the developed system should incorporate the variation of engagement angle (radial depth of cut) along the toolpath and stability limits along different machine axes.

\section{References}

1. Held M (2001) VRONI: an engineering approach to the reliable and efficient computation of Voronoi diagrams of points and line segments. Comput Geom 18(2):95-123

2. Dhanik S (2009) NC tool path evaluator and generator for high speed milling. PhD Thesis. Swiss Federal Institute of Technology, Lausanne

3. Shunmugam MS, Bhaskara Reddy SV, Narendran TT (2000) Selection of optimal conditions in multi-pass face-milling using a genetic algorithm. Int J Mach Tools Manuf 40:401-414

4. Rai JK, Brand D, Slama M, Xirouchakis P (2011) Optimal selection of cutting conditions in multi-tool milling operations using genetic algorithm. Int J Prod Res 49(10):3045-3068

5. Sönmez AI, Baykasoğlu A, Dereli T, Filiz IH (1999) Dynamic optimization of multipass milling operations via geometric programming. Int J Mach Tools Manuf 39(2):297-320

6. Dereli T, Filiz IH, Baykasoğlu A (2001) Optimizing cutting parameters in process planning of prismatic parts by using genetic algorithms. Int J Prod Res 39:3303-3328

7. Tandon V, El-Mounayri H, Kishawy H (2002) NC end milling optimization using evolutionary computation. Int J Mach Tools Manuf 42:595-605

8. Baykasoğlu A, Dereli T (2002) Novel algorithmic approach to generate the 'number of passes' and 'depth of cuts' for the optimization routines of multipass machining. Int J Prod Res 40(7):1549-1565

9. Wang ZG, Wong YS, Rahman M (2004) Optimisation of multi-pass milling using genetic algorithm and genetic simulated annealing. Int J Adv Manuf Technol 24:727-732

10. Wang ZG, Rahman M, Wong YS, Sun J (2005) Optimization of multi-pass milling using parallel genetic algorithm and parallel genetic simulated annealing. Int J Mach Tools Manuf 45(15):1726-1734

11. Budak E (2006) Analytical models for high performance milling. Part II: process dynamics and stability. Int J Mach Tools Manuf 46(12-13):1489-1499

12. Tobias S, Fishwick W (1958) A theory of regenerative chatter. The Engineer 205:199-203 
13. Tlusty J, Polacek M (1963) The stability of machine tools against self-excited vibrations in machining. In: Proceedings of the ASME International Research in Production Engineering, Pittsburgh, USA pp 456-474

14. Merritt H (1965) Theory of self-excited machine tool chatter. J Eng Ind 87:447-454

15. Faassen RPH, Van de Wouw N, Oosterling JAJ, Nijmeijer $\mathrm{H}$ (2003) Prediction of regenerative chatter by modelling and analysis of high-speed milling. Int J Mach Tools Manuf 43(14):1437-1446

16. Balachandran B (2001) Nonlinear dynamics of milling processes. Philos Trans R Soc Lond Ser A: Math Phys Eng Sci 359(1781):793-819

17. Wiercigroch M, Budak E (2001) Sources of nonlinearities, chatter generation and suppression in metal cutting. Philos Trans R Soc Lond Ser A: Math Phys Eng Sci 359:663693

18. Altintas Y, Weck M (2004) Chatter stability of metal cutting and grinding. CIRP Ann Manuf Technol 53:619-642

19. Quintana G, Ciurana J (2011) Chatter in machining processes: a review. Int J Mach Tools Manuf 51(5):363-376

20. Altintas Y, Budak E (1995) Analytical prediction of stability lobes in milling. CIRP Ann Manuf Technol 44:357-362
21. Tekeli A, Budak E (2005) Maximization of chatter-free material removal rate in end milling using analytical methods. Mach Sci Technol 9(2):147-167

22. Palanisamy P, Rajendran I, Shanmugasundaram S (2007) Optimization of machining parameters using genetic algorithm and experimental validation for end-milling operations. Int $\mathbf{J}$ Adv Manuf Technol 32:644-655

23. Budak E, Altintas Y (1994) Peripheral milling conditions for improved dimensional accuracy. Int J Mach Tools Manuf 34(7):907-918

24. Altintas Y (2000) Manufacturing automation: metal cutting mechanics, machine tool vibrations and $\mathrm{CNC}$ design. Cambridge University Press, Cambridge

25. Rai JK (2008) FEM-MILL: a finite element based 3D transient milling simulation environment for process plan verification and optimization. $\mathrm{PhD}$ Thesis

26. Budak E (2006) Analytical models for high performance milling part I: cutting forces, structural deformations and tolerance integrity. Int J Mach Tools Manuf 46(12-13):14781488

27. Delio T, Tlusty J, Smith S (1992) Use of audio signals for chatter detection and control. J Eng Ind Trans ASME 114(2):146157 